\title{
APPLICATION OF BIAS-CORRECTION AND DOWNSCALING METHOD TO KALU GANGA BASIN IN SRI LANKA
}

\author{
Cho Thanda NYUNT ${ }^{1}$, Hiroki YAMAMOTO ${ }^{2}$, Akio YAMAMOTO ${ }^{3}$, \\ Toshihoro NEMOTO ${ }^{4}$, Masaru KITSUREGAWA ${ }^{5}$ and Toshio KOIKE6 \\ ${ }^{1}$ Student Member of JSCE, Ph. D. Student, Dept. of Civil Eng., University of Tokyo (Bunkyo-ku, Tokyo 113-8656, \\ Japan) \\ ${ }^{2}$ Student Member of JSCE, Master Student, Dept. of Civil Eng., University of Tokyo (Bunkyo-ku, Tokyo 113-8656, \\ Japan) \\ ${ }^{3}$ Researcher, Institute Industrial Science, University of Tokyo (Meguro-ku, Tokyo 153-8505, Japan) \\ ${ }^{4}$ Associate Professor, Institute Industrial Science, University of Tokyo (Meguro-ku, Tokyo 153-8505, Japan) \\ ${ }^{5}$ Professor, Institute Industrial Science, University of Tokyo (Meguro-ku, Tokyo 153-8505, Japan) \\ ${ }^{6}$ Member of JSCE, Dr. Eng., Professor, Dept. of Civil Eng., University of Tokyo (Bunkyo-ku, Tokyo 113-8656, \\ Japan)
}

\begin{abstract}
Climate change impact assessments for regional or local studies are mainly based on the general circulation models GCMs under the different emission scenarios. Downscaling of selected GCM after bias-correction can address the gap of resolutions with some merits and limitation for application at basin-scale hydrologic simulation. This paper describes how to select the appropriate GCMs and how to develop bias-correction and downscaling methods for GCMs precipitation. Bias-corrected scheme removes the large bias of GCMs precipitation. This method of downscaling is also comparable to the basin scale mean intensity, annual precipitation and inter-annual monthly precipitation. All of corrected GCMs rainfall presented the increasing trend not only in extreme rainfall but also in seasonal climatology in the Kalu Ganga basin in near future.
\end{abstract}

Key Words : bias-correction, downscaling method,, GCM, GSMaP, Precipitation, spatial distribution

\section{INTRODUCTION}

Climate models are the primary tool to evaluates the projected future response of the atmosphere-land-ocean system to changing atmospheric composition $^{1,2)}$ and they underpin most climate change impact studies ${ }^{3)}$. Generally, coupled general circulation models (GCMs) are the most widely applied tools for studying the climate change ${ }^{4)}$. However, there is a big gap of grid resolution between GCMs and catchment-scale hydrology models. To link this mismatch, downscaling of GCMs data is an essential tool for regional and local impact studies. Downscaling is the process of transforming information from climate models at coarse resolutions to a fine spatial resolution ${ }^{5)}$. There are two main types of downscaling; dynamical and statistical downscaling.
Dynamical downscaling refers to the nesting to the fine scale resolution in the large-scale resolution preserving some spatial correlation. However, this method is computationally expensive and it is impossible for multi-decade simulations of different $\mathrm{GCMs}^{5}$. Statistical downscaling involves the data analysis by defining the relationship between a large-scale circulation and local-scale circulation. Compared with dynamical downscaling, it is very cheap in computation and some techniques for simultaneous downscaling for precipitation have been developed ${ }^{6,7)}$. Both of the methods require to handle the biases of GCMs precipitation.

Selection of proper GCMs among various GCM is crucial for multi-modle analysis. This selection is conducted according to the performance of GCM from Climate Model Inter-comparison Project 3 (CMIP3). Most of the GCMs precipitation show main problems of low intensity in heavy rainfall, 
low seasonal representation and small intensity but long rainy days called drizzle. In this study, we focus on the bias-correction of GCM to reduce these biases. Annual maximum rainfall, normal rainfall and numbers of no rain day are bias-corrected statistically.

Downscaling can resolve the spatial resolution of GCM. Considering the limitation of in-situ data availability, we need to consider a satellite-based method, which can be applied to catchment-scale impact studies widely. We investigated a combination of a limited number of in-situ rain gauges and GSMaP for solving the issue in this study. Finally, the coupled method of the bias-correction and downscaling is evaluated by using statistical parameters of the observed data and the corrected model outputs.

\section{STUDY AREA AND DATA}

The Kalu Ganga river is about $130 \mathrm{~km}$ long which extends from $80^{\circ}$ to $80.67^{\circ} \mathrm{E}$ and $6.4167^{\circ}$ to $6.83^{\circ} \mathrm{N}$, locates in the southwestern of Sri Lanka and runs into the Indian Ocean. The floods occur during the Southwest monsoon season frequently due to high annual average precipitation around $4000 \mathrm{~mm}$ and topographic characteristics especially steep gradient in upstream and very low flood plain in downstream. Therefore, the damages to the socioeconomic profile are significantly high since lower flood plain is densely populated and potential area of rice production ${ }^{8)}$.

The daily precipitation data is available from the one of the demonstration projects of GEOSS/Asian Water Cycle Initiative (AWCI).The observed data set for baseline period includes 26 in-situ stations distributed over the Kalu Ganga river basin in Sri Lanka. Daily areal average precipitation of 23 different GCMs output of Coupled Model Inter-comparison Project 3 (CMIP3) were obtained from Data Integration and Analysis System (DIAS) server. In this study, we consider the 1981-2000 as the baseline period and 2046-2065 as the projected period covering the SRES A1B emission scenarios ${ }^{9)}$.

The Global Satellite Mapping of Precipitation (GSMaP) project has been established by Japan Science and Technology Agency (JST) since 2002. GSMaP_MVK product has been developed by integrating passive microwave radiometer data with infrared radiometer (IR) data in order to have high temporal ( 1 hour) and spatial (0.1 degree) resolution of global precipitation estimates ${ }^{10) 11) 12}$. In this study, GSMaP_MVK daily precipitation from 2003 to 2008 is utlized to get the areal average spatial distributed factors for downscaling of GCM in the Kalu Ganga basin in each month.

\section{METHODS}

\section{(1)GCM selections}

GCMs can have large biases such as low extreme intensity and low intensity long rain day when it comes to reproduce the regional or local features of climate ${ }^{9)}$. Areal average of 23 GCMs daily rainfall for the baseline (1981-2000) and the future (2046-2065) scenario periods for study area were downloaded from CMIP3 models output developed by the Data Integration and Analysis System (DIAS) project. The observed areal average rainfall (1981-2000) has been prepared by using thiessen polygon interpolation from 26 stations located within the basin.

In Fig. 1, the outline of this study is summarized. First, it is necessary to choose proper GCM, which can reproduce the seasonal evolution of the Asian summer monsoon in base-line period. As for this criteria, we choose spatial correlation (Scorr) and root mean square error (RMSE) of climatologically key parameters such as monthly averaged precipitation, outgoing longwave radiation, mean sea level pressure, sea surface temperature, 850hpa geo-potential height in the Asia-Pacific region including the Tibetan Plateau. GPCP precipitation and JRA Reanalysis data are used as references. By comparing 4 month (May-August) average of Scorr and RMSE of each GCM with average of all GCM, GCM which has higher Scorr and smaller RMSE than average of all GCM account as an appropriate GCM and it is given score as 1 for each parameter. If a GCM has lower Scorr and larger RMSE than averages, it is given -1 . In the other cases, zero is given. Then, according to the total scores of each GCM, we selected 9 GCMs having equal or higher than 5 of totals scores 10 in this study. The selected GCMs are tabulatd in Table 1.

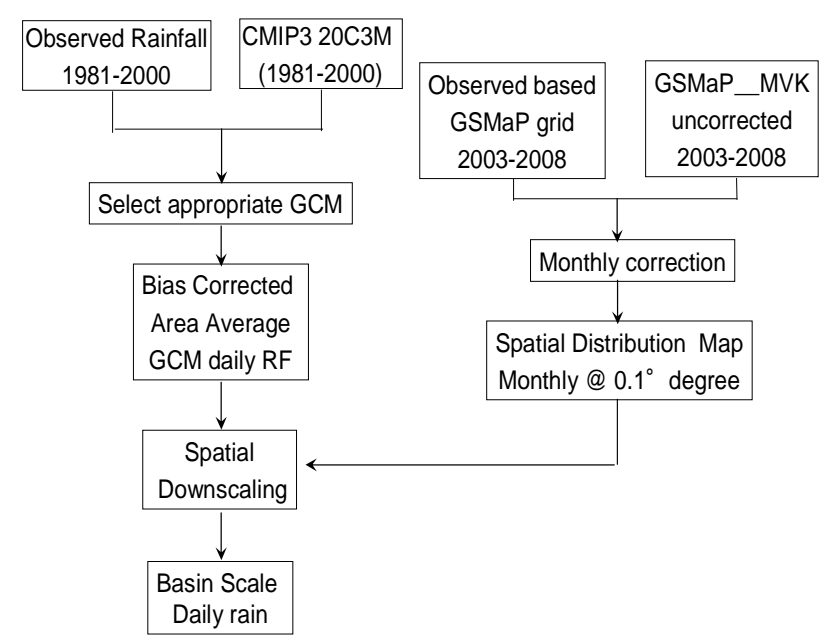

Fig.1 Study frame work 
Table 1. Selected GCMs

\begin{tabular}{|llll|}
\hline No & GCMs & Scores & Country \\
\hline 1 & gfdl_cm2_1 & 9 & USA \\
2 & cccma_cgcm3_1 & 8 & Canada \\
3 & cccma_cgcm3_1_t63 & 8 & Canada \\
4 & gfdl_cm2_0 & 8 & USA \\
5 & miroc3_2_medres & 7 & Japan \\
6 & mpi_echam5 & 7 & Germany \\
7 & ingv_echam4 & 6 & Italy \\
8 & miroc3_2_hires & 6 & Japan \\
9 & giss_aom & 5 & USA \\
\hline
\end{tabular}

\section{(2) Bias-correction}

Methods for mapping one distribution onto another are well established in probabilistic modeling and it has been used to correct bias of both monthly and daily GCM precipitation ${ }^{13), 14)}$. After selecting 9 proper GCMs out of 23 GCMs, bias-correction was done for extreme rainfall, normal rainfall and number of no rain days of GCM.

The annual maximum rainfall for baseline period are selected and the rainfall which is greater than the minimum of 20 maxima annual rainfall is defined as extreme rainfall and mapping the probability distribution function of observed extreme rainfall onto the GCMs extremes rainfall. Lognormal and Gumbel distribution for extreme rainfall varied with Weibull, Hazen and Cunnane probability plotting positions, totally 6 alternatives of probability plotting types were considered for choosing the best-fit distribution of observed extreme rainfall. Then, best-fit distribution function is applied to all GCMs annual maximum rainfall for bias-correction of extreme rainfall according to Eq.1.

$$
\tilde{x}_{G C M}=F_{G C M}{ }^{-1}\left(F_{O B S}(\tilde{x})\right)
$$

$\tilde{x}$ means bias-corrected annual extreme rainfall for every year. $\mathrm{F}(\mathrm{)})$ and $\mathrm{F}^{-1}(\mathrm{)}$ denoting the distribution function and its inverse and the subscripts indicate GCM or observed annual maximum rainfall.

The numbers of no rain day is corrected by using by ranking order statistic. A threshold of each GCM rainfall is identified by using the rank, which shows the smallest rainfall in the descending order of the observed rainfall. Each GCM rainfall less than this threshold are defined as zero. If GCM daily rainfall is less than this threshold, it becomes zero and counts as no rain day in GCM.

Normal rain is defined as the rainfall having less than the minimum of annual maxima of 20 years and greater than the threshold. The difference between monthly average rainfall of GCM and observed excluding annual maximum rainfall within the baseline period is assigned as the correction factor for each month of normal rain days. In this way, GCMs areal average daily mean intensity and the relative frequency of rainy days of control period are bias-corrected.

Then, similar correction method has applied to extreme rainfall and normal rainfall under the SRES A1B scenario. For no rain day correction, the threshold of each GCM is same for past and future. This means it can be evident the change in dry spell length between past and future.

\section{(3)Downscaling}

Downscaling is done by GSMaP based statistical downscaling. This method refers as BC+Map downscaling; BC stands for bias-correction and and MaP stands for downscaled map. After GSMaP rainfall monthly correction between gauge station based GSMaP gridded rainfall and GSMaP uncorrected rainfall from 2003-2008 had done, areal average spatial weight for each grid of GSMaP is calculated for each month. Gauge based GSMaP gridded rainfall is available from Inverse Distance Weight (IDW) interpolation between in-situ stations and GSMaP grid centre. Then, bias-corrected GCMs rainfall is downscaled by using spatial weight distribution. Notice that, this downscaling scheme did not correct the frequency of rainy days of GSMaP and it is similar as a factor correction. The corrected GSMaP based spatial weights are used for downscaling but not the corrected GSMaP value itself. Then the performance of downscaled map is evaluated by applying other period 1981-2000 and 2046-2065. Finally, downscaled rainfall are evaluated by annual average rainfall, inter annual variation, mean intensity, standard deviation, bias and root mean squared error (RMSE) of each GCM. Bias and RMSE are defined as follows:

$$
\begin{aligned}
& \text { bias }=\sum_{i=1}^{n}\left(S_{i}-O_{i}\right) / \sum O_{i} \\
& \text { RMSE }=\sqrt{\sum_{i=1}^{n}\left(S_{i}-O_{i}\right)^{2} / n}
\end{aligned}
$$

where $\mathrm{n}$ is the total number of time series, $\mathrm{S}_{\mathrm{i}}$ is the simulated result and $\mathrm{O}_{\mathrm{i}}$ is the observed data.

\section{RESULTS AND DISCUSSIONS}

\section{(1) Bias-correction}

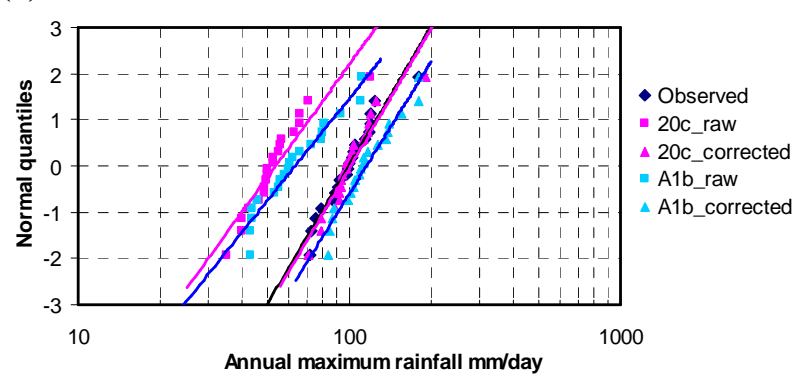

Fig. 2 Probability plot for extreme rainfall 


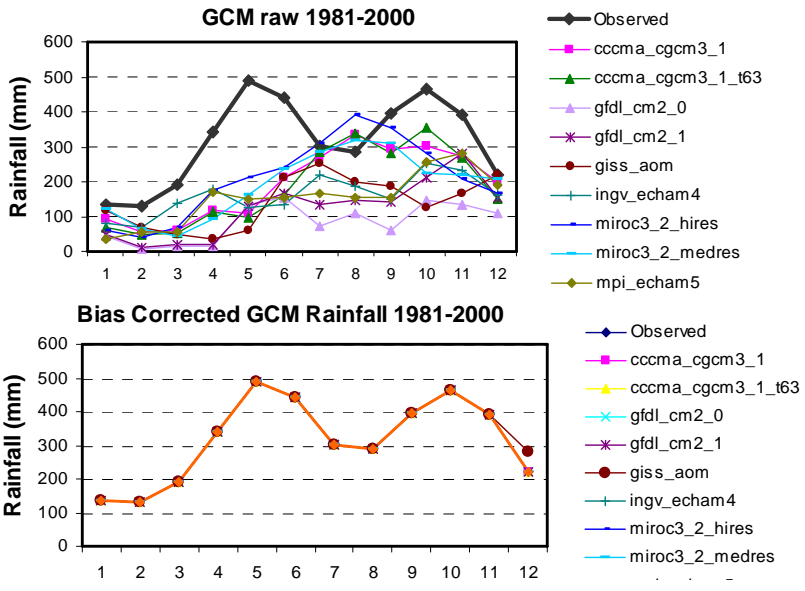

Fig. 3 Seasonal cycle of precipitation for Kanlu Ganga basin before and after bias-correction

Bias correction of extreme rainfall results is shown in Fig.2 using Cunnane plotting positions to check the best fit distribution for miroc3_2hires model. Pink trend line refers to 1981-2000 extremes and blue trend line shows for 2046-2065 extremes. The trend lines for observed (black) and bias-corrected miroc3_2hires extreme rainfall overlap after correction. The shift between lines means bias was corrected and the gap between control period and projected period describes extreme rainfall is likely to be higher in 2046-2065.

Fig.3 presents the rainfall climatology of all GCMs for the Kanlu Ganga basin before and after bias-correction. Most of the GCMs cannot trap the seasonal cycle of rainfall but this method notably transforms the same seasonal patterns as observed ones after bias-correction. This figure represents the two distinct periods of rainy season in this basin. This means bias-correction method performance is good enough to keep the seasonal characteristics of the basin. The bias -corrected result for number of no rain day is shown in Fig.4. The observed extreme rainfall is blue, bias-corrected GCM results are white wave bar for 1981-2000, and red spot bar for 2046-2065. It shows number of no rain day will increase in future from 9GCM ensemble. This mean this basin will suffer more intense rainfall in monsoon season and longer dry spell in projected period (2046-2065) by analyzing extreme and frequency of bias-corrected rainfall.

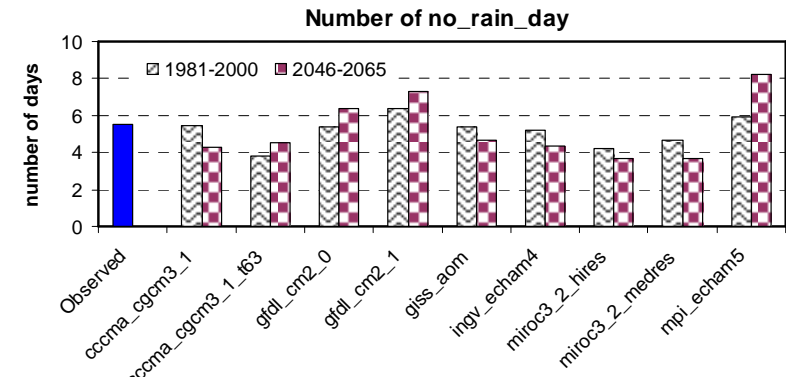

Fig.4 Frequency of no rain day for present and future

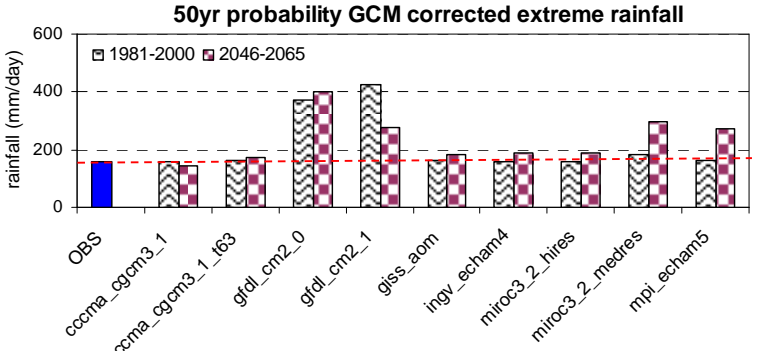

Fig. 5 50-year probability of extreme rainfall

For the basin-scale water resources management and planning, frequency analysis plays an important role and it is used to estimate the probability of occurrence of extreme rainfall. 50-year recurrence interval of extreme rainfall simulated by bias-correction is plot in Fig.5. Bias-corrected results of seven GCMs extreme rainfalls are as equal as the observed but two GCMs perform overestimated extreme rainfall in both periods. By averaging all GCMs, it shows around $100 \mathrm{~mm}$ per day is likely to increase for 1 in 50 chances. All of GCMs except one produce extreme rainfall is likely to increase in future.

\section{(2)Downscaling}

After bias-correction had finished, downscaling was done by areal average spatial weights over the basin. Fig.6 presents the spatial distributed weights for each month based on GSMaP monthly corrected rainfall of the Kalu Ganga basin from 2003-2008. By using the monthly spatially distributed weight over the basin, bias-corrected GCM daily rainfall is distributed to the basin. In this way, bias-corrected rainfall is downscaled temporally and spatially based on statistic. This map refers as a surrogate of GCM for downscaling. But the monthly factors accomplish the extra-ordinary values of extreme rainfall as a result the weights are somehow overestimate in basin area average rainfall. This mean although bias was corrected monthly basic, bias still exit in spatially distribution.

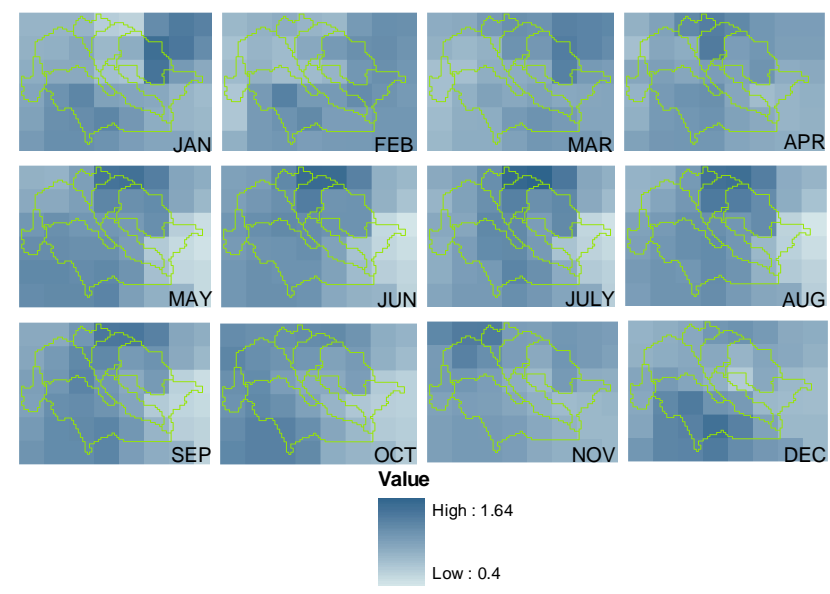

Fig.6 GSMaP spatial distributed weight map for each month 


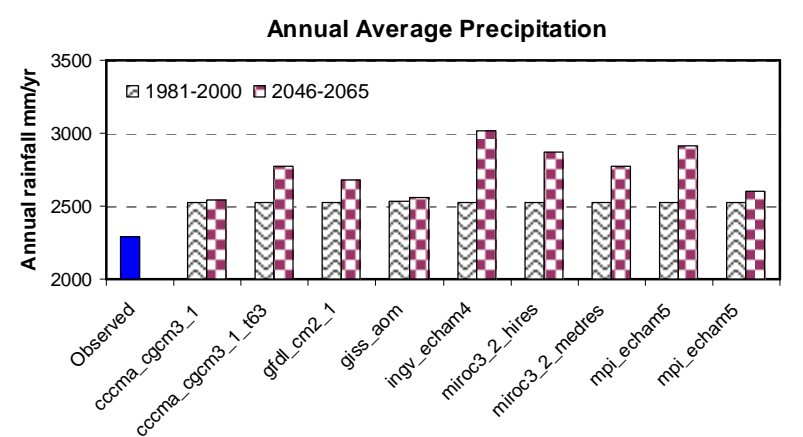

Fig.7 Annual average precipitation

As a consequences, annual average rainfall in this basin overestimates $230 \mathrm{~mm} /$ year compared with observed. Bias-corrected and downscaled annual average rainfall for past and future comparison of each GCM is illustrated in Fig.7. All of GCM show the increasing trend in annual average rainfall in near future (2046-2065) and 9GCM ensemble gives over $200 \mathrm{~mm}$ per year will increase.

For inter-annual variation, it can simulate very well and describe seasonal pattern clearly. The results are shown in Fig. 8. The first one compares observed versus 9GCM and all GCM produce almost the same amount of rainfall in all GCM in every month because of areal average spatial weight distribution in the basin after bias-correction. The second figure describes the difference between the control and projected periods. It can conclude higher intensity nearly throughout the year and more intense in monsoon season.

Visual inspection of spatial variation of bias-corrected and statistically spatial-downscaled rainfall versus observed rainfall for October from Miroc3_2_hires model was shown in Fig.9. Although observed rainfall intensity was low in middle and west part of the basin, downscaled rainfall produced more intensity in that area because bias was corrected on monthly basic and the spatial weight was good enough to capture the same as observed but still some biases exited.
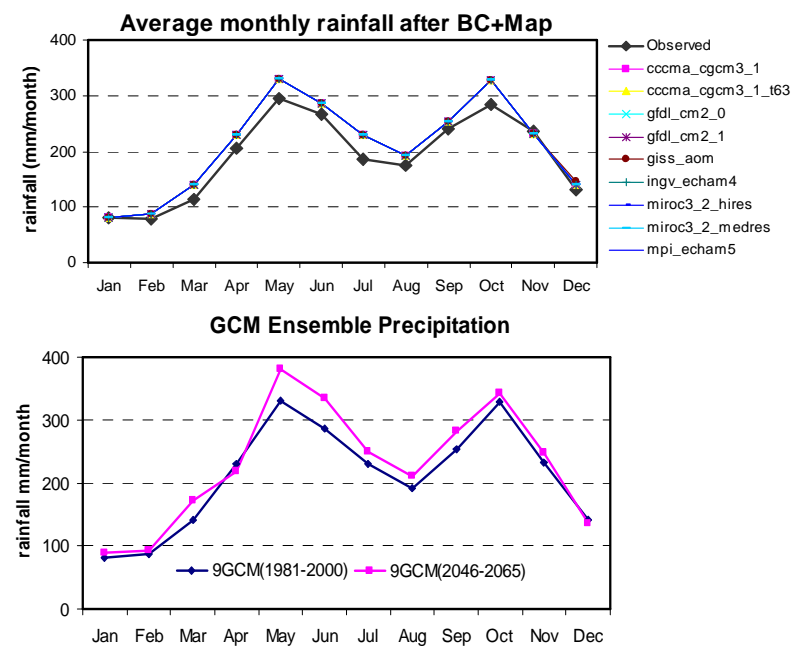

Fig. 8 Seasonal variation of precipitation

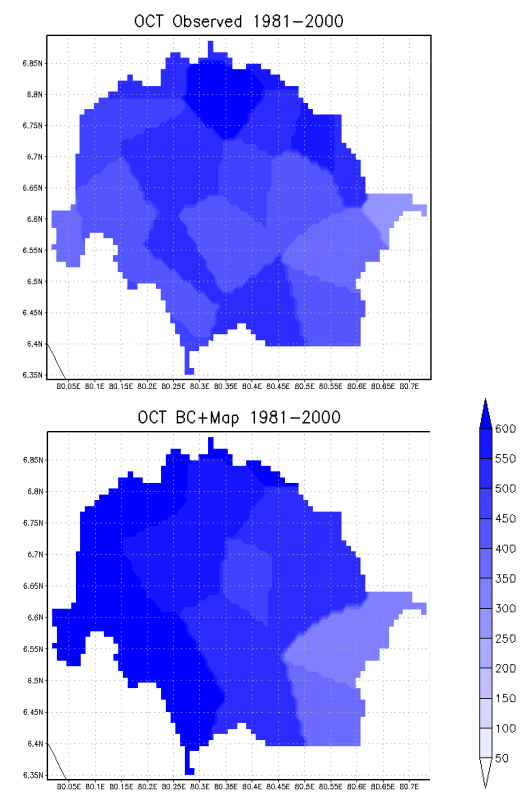

Fig.9 Observed and BC+Map downscaled rain ( $\mathrm{mm})$ in October

Statistical parameters indicating the correspondence of bias-corrected GCM from field observation for daily mean rainfall amount are provided in Table 2. Areal average mean daily precipitations were relatively comparable with observed mean precipitation. Bias and root mean squared error (RMSE) were calculated using Eq.2 and Eq. 3. The bias of $10 \%$ is the maximum in downscaled rainfall of 9 GCM. The standard deviation of daily precipitation during control period is $8.5 \mathrm{~mm}$ per day to $13 \mathrm{~mm}$ per day. The root mean squared error varied in the range between $11 \mathrm{~mm}$ per day to $14 \mathrm{~mm}$ per day. BC+Map method is the downscaling from the available satellite products, which have high temporal and spatial resolution. Bias-correction and GSMaP spatial weight downscaling method can be applicable to every basin, which is poorly gauges, or not. This downscaling method was developed to check the applicability of GSMaP satellite products and it takes the main advantages of satellite based rainfall products, which are available at the global scale with $0.1^{\circ}$ resolution with high temporal resolution with daily or hourly time scale.

Table 2. Performance criteria of downscaling methods

\begin{tabular}{|l|l|l|l|l|}
\hline BC+Map & mean & SD & bias & RMSE \\
\hline observed & 6.28 & 8.48 & & \\
\hline cccma_cgcm3_1 & 6.93 & 7.86 & 0.1 & 11.09 \\
\hline cccma_cgcm_t63 & 6.93 & 7.98 & 0.1 & 11.18 \\
\hline gcm & 6.93 & 13.15 & 0.1 & 15.2 \\
\hline giss_aom & 6.94 & 9.36 & 0.1 & 12.26 \\
\hline ingv_echam4 & 6.93 & 9.88 & 0.1 & 12.65 \\
\hline miroc3_2hires & 6.93 & 10.11 & 0.1 & 12.93 \\
\hline miroc3_2medres & 6.93 & 10.88 & 0.1 & 13.06 \\
\hline mpi_echam5 & 6.93 & 11.9 & 0.1 & 14.23 \\
\hline
\end{tabular}




\section{CONCLUSIONS}

This paper explored the way to choose the proper GCMs from the various diversity of GCM. Then explained how to set up the bias-correction for GCMs precipitation related with the extreme rainfall, normal rainfall and frequency of no rain day. The output of 9 GCMs included in the $4^{\text {th }}$ IPCC assessment report were analyzed. This method was applied both control period (1981-2000) and the projected period (2046-2065). The quality of bias-correction was investigated through not only probability plot for extreme rainfall but also monthly inter-annual variability. Moreover, frequency of no rain days was also checked for evaluation of bias-correction.

It was found that the probabilistic bias correction method was capable to correct large bias of rainfall. For the next step, GSMaP based areal average spatial weight downscaling had done. The downscaled results showed it could produce the daily mean precipitation, seasonal cycles and annual precipitation reasonably. For spatially-weighted downscaling, spatial weights were come from monthly correction of GSMaP products and it did not consider the extreme events and frequency correction of GSMaP. However, the outcome is acceptable in spatial and temporal downscaling. Therefore, the effect of the bias from extreme event and frequency of rainfall should be included in GSMaP products correction. Moreover, it should be checked whether GSMaP spatially-distributed weight map would be applicable to any other basin with poor gauges or not. Furthermore, the correction method for GSMaP products needs more improvement to accomplish better spatial and temporal resolution for basin scale. Finally, both of methods should be evaluated against discharge flow to check the performance of climate change impact studies at the basin scale.

ACKNOWLEDGMENT: This study was supported by the Japanese Ministry of Education, Science, Support and Culture (MEXT). The GCM data used in this study was developed by Data Integration and Analysis System (DIAS) project. The GSMaP project was sponsored by JST-CREST and promoted by the JAXA Precipitation Measuring Mission (PMM) Science Team.

\section{REFERENCES}

1) MacCracken, M. C., Barron, E. J., Easterling, D. R., Felzer, B. S., and Karl, T. R.: Climate change scenarios for the U.S. national assessment, B. Am. Meteorol. Soc., pp. 1711-1723, doi:10.1175/BAMS-84-12-1711, 2003.

2) Stocker, T. F., Clarke, G. K. C., Le Treut, H., Lindzen, R. S.,
Meleshko, V. P., Mugara, R. K., Palmer, T. N., Pierrehumbert, R. T., Sellers, P. J., Trenberth, K. E., and Willebrand, J.:Physical climate processes and feedbacks, in: Climate Change 2001: The Scientific Basis, edited by: Houghton, J. T., Ding, Y., Griggs, D. J., Noguer, M., van der Linden, P. J., and Xiaosu, D., Cambridge University Press, pp. 417-470, 2001.

3) Wilby, R. L. and Harris, I.: A framework for assessing uncertainties in climate change impacts: low-flow scenarios for the River Thames, UK, Water Resour. Res., 42, W02419, doi:10.1029/2005WR004065, 2006.

4) Jean-Philippe Vidal;Steven D. Wade: Multimodel projections of catchment-scale precipitation regime, J. Hydrol., Vol. 353, pp. 143-158, 2008.

5) E.P. Maurer and H.G.Hidalgo: Utility of daily vs. monthly large-scale climate data: an intercomparison of two statistical downscaling methods, Hydrol. Earth Syst. Sci., Vol. 12, pp.551-563, 2008

6) Harpham, C. and Wilby, R. L.: Multi-site downscaling of heavy daily precipitation occurrence and amounts, $J$. Hydrol., 312, pp. 235-255, 2005.

7) Wilks, D. S.: Multisite downscaling of daily precipitation with a stochastic weather generator, Climate Res., 11, pp.125-136, 1999.

8) A.D. Amipitiyawatta, Shenglian Guo: Precipitation trends in the Kalu Ganga basin in Srilanka, J. Agri Sci., vol4, no.1, 2009

9) M.E.Elshamy, I.A. Seuerstad, and A.Sorteberg; Impacts of climate change on Blue Nile flows using bias-corrected GCM scenarios: Hydrol. Earth Syst. Sci., Vol.13, pp. 551-565, 2009

10) T. Kubota, S. Shige, H. Hashizume, K. Aonashi, N. Takahashi, S. Seto, M. Hirose, Y. N. Takayabu, K. Nakagawa, K. Iwanami, T. Ushio, M. Kachi, and K. Okamoto, 2007: Global Precipitation Map using Satelliteborne Microwave Radiometers by the GSMaP Project : Production and Validation, IEEE Trans. Geosci. Remote Sens., Vol. 45, No. 7, pp.2259-2275

11) K. Aonashi, J. Awaka, M. Hirose, T. Kozu, T. Kubota, G. Liu, S. Shige, S. Kida, S. Seto, N. Takahashi, and Y. N. Takayabu, 2009: GSMaP passive, microwave precipitation retrieval algorithm: Algorithm description and validation. $J$. Meteor. Soc. Japan, 87A, pp.119-136

12) T. Ushio, T. Kubota, S. Shige, K. Okamoto, K. Aonashi, T. Inoue, N. Takahashi, T. Iguchi, M. Kachi, R. Oki, T. Morimoto, and Z. Kawasaki, 2009:A Kalman filter approach to the Global Satellite Mapping of Precipitation (GSMaP) from combined passive microwave and infrared radiometric data. J. Meteor. Soc. Japan, 87A, pp.137-151

13) Wood, A. W., Maurer, E. P., Kumar, A., and Lettenmaier, D. P.: Long-range experimental hydrologic forecasting for the eastern United States, J. Geophys. Res.-Atmos., 107, pp. 4429, 2002

14) Ines, A. V. M. and Hansen, J. W.: Bias correction of daily GCM rainfall for crop simulation studies, Agricultural and Forest Meteorology, 138, pp. 44-53, 2006.

(Received September 30, 2011) 